S E Ç Ã O TE M Á T I C A

\title{
A Bola de Neve avança, o diabo retrocede: preparando Davis para a batalha e o domínio através de um marketing de guerra santa em trânsito \\ Bola de Neve goes forward, the Devil falls back: training davids for the battle and conquest through the in-transit Holy War Marketing
}

Eduardo Meinberg de Albuquerque Maranhão Filho*

Resumo: Demonstro aqui algumas das formas como o marketing de guerra santa da Bola de Neve Church (BDN) se apresenta, em um cenário de espetacularização/midiatizaçáo e relacionado a um discurso bélico que enfatiza as teologias da Batalha e do Domínio Espiritual. A apropriaçáo da guerra e da conquista por territórios como alegorias discursivas para promover esta agência religiosa, associada à doutrinação de fiéis, é o assunto central deste artigo, escrito a partir de observaçáo participante, participaçáo observante, notas de caderno de campo e análise de sites desta agência evangélica.

Palavras-chave: Bola de Neve Church, marketing religioso, identidade religiosa, batalha espiritual, domínio espiritual.

Abstract: The so-called holy war marketing of the Pentecostal Church Bola de Neve based on the church's Theology of Spiritual Battle and Domain is one of many expressions of the growing "spectularization" and "mediatization" of the Brazilian religious landscape. The article, written from the perspective of an observant participant, focusses on warlike metaphors that frequently appear in the Church's discourses, including the Churches websites.

Key words: Bola de Neve Church, religious marketing, religious identity, spiritual warfare, spiritual domain.

\footnotetext{
* Doutorando em História Social pela Universidade de São Paulo (USP), mestre em História pela Universidade do Estado de Santa Catarina (UDESC) e especialista em Marketing e Comunicação Social pela Fundação Cásper Líbero. Contato: edumeinberg@gmail.com
} 


\section{Introdução}

Mantenha suas forças concentradas na melhor forma possível. Antecipe-se a todos o máximo que puder. Karl von Clausewitz

No que se segue, demonstro algumas das maneiras como a Bola de Neve Church (BDN) - agência evangélica de características majoritariamente neopentecostais - apresenta seu discurso beligerante, no qual a guerra por territórios espirituais ou/e do mercado religioso é marcada pelas teologias da Batalha e Domínio Espiritual, referentes discursivos de seu marketing de guerra santa - em trânsito.

Esta pesquisa de inspiração etnográfica foi feita a partir de observação participante/participação observante entre 2005 e 2011 e em 2012, ${ }^{1}$ notas de caderno de campo, leitura bibliográfica e análise de sites desta firma religiosa, especialmente durante o período de realização de minha dissertação de mestrado sobre a mesma. ${ }^{2}$

$\mathrm{O}$ artigo se estrutura a partir de notas sobre o marketing de guerra santa da $\mathrm{BDN}$, que, assim como a própria agência, experimenta trânsitos em direção à criação e atendimento de demandas de fiéis, traz provocaçóes referentes a conceitos que costumamos usar para definir fenômenos religiosos e apresenta, através de parte mais descritiva, o discurso bélico da BDN, identificado em eventos, ministérios de evangelismo e na campanha/apoio à candidatura de políticos próprios. Tal discurso é responsável pela doutrinaçáo de fiéis e funciona como agenciador da divulgação e consolidação desta firma evangélica.

Analisar a BDN é um trabalho em processo, já que a própria agência encontra-se em constante fluxo de amoldamento de seu discurso e identidade, caracterizados

\footnotetext{
${ }^{1}$ No verão de 2005 me mudei de São Paulo para Florianópolis, conhecendo a sede da filial local da BDN, conhecida como Bola de Neve Floripa, que ficava no Rio Tavares, no Campeche. Essa primeira visita marcou minha entrada em campo. Após alguns meses de frequência, fui convidado a participar do curso de formaçáo de líderes de células. Depois da conclusão do curso, fui convidado a me tornar líder, mas recusei o convite por não concordar com as diretrizes da igreja. A partir de 2006, frequentei a BDN Floripa com menor intensidade, visitando outras unidades da BDN, como a de Balneário Camboriú e a sede em Sáo Paulo, e outras agências evangélicas de Florianópolis. Em 2010, prossegui minha observação participante - de modo pouco intenso - na BDN SP, iniciando a publicaçáo de alguns trabalhos. Em 2011 não realizei novas pesquisas sobre a agência., Em 2012, retomei minha observação participante na BDN Floripa, a fim de acompanhar suas inovaçôes e continuidades. Nesse momento, fui convidado a retornar à igreja e participar de ministérios, dentre estes, o de louvor evangelístico, a fim de cantar gospel rock e reggae. Todas as informaçóes descritas neste artigo foram obtidas no período em que a liderança da BDN foi comunicada sobre minha pesquisa.

2 Minha dissertação "A grande onda vai te pegar: Mercado, mídia e espetáculo da fé na Bola de Neve Church", foi defendida em fevereiro de 2010 e orientada pelos professores Márcia Ramos de Oliveira (UDESC) e Artur Cesar Isaia (UFSC).
} 
por movimentos de solidificação acompanhada de derretimento - portanto, este texto não pretende ser conclusivo.

\title{
Marketing de guerra santa em trânsito
}

\author{
O inimigo avança, retiramos. \\ O inimigo acampa, provocamos. \\ O inimigo cansa, atacamos. \\ $\mathrm{O}$ inimigo se retira, perseguimos. \\ Mao Tsé-Tung
}

Para Al Ries e Jack Trout, autores de Marketing de Guerra, o livro On War ("Vom Kriege"), de 1832, escrito pelo general prussiano Von Clausewitz, é "o melhor livro de marketing escrito até hoje," já que suas propostas sobre estratégias de combate podem ser facilmente assumidas e praticadas pelos atuais gerenciadores de mercado. Este marketing de guerra é combatido em "campos de batalha de apenas 15 centímetros": as mentes de estrategistas e de consumidores. ${ }^{3}$

A expressão marketing de guerra refere-se às semelhanças entre gerenciamentos militar e de mercado, em que as empresas devem "aprender como atacar pela frente e pelos flancos sua concorrência, defender suas posiçóes e como e quando fazer guerrilha." ${ }^{\prime 4}$ Constituem-se, assim, quatro formas de marketing de guerra: defensiva, ofensiva, de flanqueamento e de guerrilha.

A primeira caracteriza-se pela proteção do território feita pelo líder do mercado; a segunda, pelo ataque direto a este líder, realizado pelo (s) líder (es) mais próximo (s); a de flanqueamento, pela aposta na inovaçáo como forma de conquista; e a de guerrilha, pelo princípio de que se deve "encontrar um segmento de mercado bastante pequeno para defender" e, assim, "tornar-se um peixe grande num pequeno açude." 5

Adaptando tais conceitos para o mercado religioso, convencionei marketing de guerra santa a criação, apropriação e resignificação de estratégias de gerenciamento militar e/ou empresarial, efetuadas pelas agências religiosas. ${ }^{6} \mathrm{O}$ objetivo

\footnotetext{
3 A. RIES e J. TROUT, Marketing de Guerra, p. 45.

${ }^{4}$ A. RIES e J. TROUT, Marketing de Guerra, p. 15.

5 A. RIES e J. TROUT, Marketing de Guerra, pp. 89-94.

${ }^{6}$ A apropriação de referentes bélicos pelas agências evangélicas - e religiosas em geral - é anterior a Marketing de Guerra, de Ries e Trout. Entretanto - como esta obra costuma ser referência em cursos de marketing -, é possível que alguns líderes religiosos (alguns dos quais especializados em marketing, como Rinaldo Seixas, da BDN, e Estevam Hernandez, da Renascer) tenham tido acesso à obra e aplicado alguns de seus conceitos.
} 
$126 \mid$ Eduardo Meinberg de Albuquerque Maranhão Filho

geral destas ${ }^{7}$ é a aquisição de melhor posicionamento no mercado e da preferência e adesão do fiel-consumidor, através da oferta e do atendimento de suas demandas e expectativas religiosas. ${ }^{8}$

Ressalto que marketing de guerra santa não é um conceito "nativo", mas inspirado em observação participante/participação observante de um contexto "nativo", bélico, e uma forma encontrada para (re) pensar diferentes agenciamentos de pessoas, comunidades e instituiçôes relacionadas ao fenômeno religioso. Trata-se de expressão utilizada como chave de compreensão das estratégias de marketing religioso de agências como a $\mathrm{BDN}$ - estas, contudo, não usam tal referência metafórica.

O marketing de guerra é pensado como a adaptação de conceitos militares ao gerenciamento de mercado, enquanto o marketing de guerra santa é visto a partir de semelhanças entre gerenciamento marcial, marketing empresarial e marketing religioso, que se (con) fundem. Nessa situação de marketing, "o terreno a ser conquistado é a mente, o imaginário e o desejo do consumidor."

$\mathrm{O}$ marketing de guerra santa é marcado por um contexto ultraconcorrencial e de entre-lugare ${ }^{10}$ religiosos, no qual as estratégias - bem como as próprias agências religiosas, com seus produtos e mercadorias - são caracterizadas por deslocamentos e hibridismos, moldando-se a fim de criarem e atenderem demandas específicas.

Os entre-lugares religiosos sinalizam também para as múltiplas experiências e agenciamentos dos fiéis, vistos também em situações de entre-religiosidades. Nessa perspectiva, os fiéis são vistos com agência, ${ }^{11}$ promotores/estimuladores de mudanças nas instituiçóes, e não somente como sujeitos agenciados pelas mesmas.

$\mathrm{O}$ marketing de guerra santa é identificado pelo trânsito, deslocamento em busca da criação e satisfação de expectativas e desejos. Esta situação de marketing é relacional, havendo duplo agenciamento, tanto por parte do sujeito (individual ou coletivamente) como da firma religiosa. Tal mobilidade, de fiéis e de agências,

\footnotetext{
${ }^{7} \mathrm{O}$ conceito de agência ou firma religiosa é emprestado especialmente de teóricos do paradigma estadunidense de mercado religioso (ou das economias religiosas), como Roger Finke, James McCann, Rodney Stark, Larry Iannaconne e William Bainbridge.

${ }^{8}$ E. M. de A. MARANHÃO Fo, "Marketing de Guerra Santa": da oferta e atendimento de demandas religiosas à conquista de fiéis-consumidores. In: Horizonte, pp. 201-232.

9 E. M. de A. MARANHÃO Fo, "Marketing de Guerra Santa": da oferta e atendimento de demandas religiosas à conquista de fiéis-consumidores. In: Horizonte, p. 212.

${ }^{10} \mathrm{~A}$ noçáo de entre-lugares, que inspirou estes conceitos - em andamento - pode ser vista em H. K. BHABHA, O local da cultura.

${ }^{11} \mathrm{O}$ conceito de agência, neste sentido, é pensado como o empreendimento coletivo que ultrapassa as açóes do sujeito - e também como o comportamento das instituiçôes. Assim, sujeitos, coletivos e agências (firmas) religiosas possuem manifestaçôes de agência, ou agenciamentos.
} 
reflete identidades e discursos (individuais, coletivos e institucionais) móveis, derretidos e múltiplos.

No caso das firmas religiosas, o deslocamento se associa à concorrência por fiéis. São agências em trânsito - e também em hibridismo, por se apropriarem muitas vezes de elementos de outras expressóes religiosas em seus discursos e práticas, objetivando maiores fatias do mercado e a preferência do fiel-consumidor. ${ }^{12}$ No caso deste hibridismo, é possível se falar em situaçôes de entre-campos religiosos, isto, se a ideia de campo religioso ainda puder ser considerada conveniente para se entender as expressóes de religiosidade do contemporâneo.

As agências religiosas podem promover, dependendo de cada contexto, diferentes apresentaçóes de um marketing de guerra santa, que se hibridizam, e que podemos denominar - amparados nos conceitos de Ries e Trout - defesa santa, ataque santo, flanqueamento santo e guerrilha santa ${ }^{13}$-, vocábulos utilizados com fins pedagógicos e heurísticos.

Defesa, ataque, flanqueamento e guerrilha, utilizados aqui como conceitos são termos apropriados por agências religiosas que se valem de um arsenal discursivo caracterizado por referências bélicas -, o que aponta para uma semelhança entre discursos militares e religiosos, constitutiva de um marketing de guerra santa. ${ }^{14}$

O marketing de guerra santa promove-se fazendo marketing com a "guerra santa": referentes beligerantes são usados como forma de promoção/consolidação da agência. Nesse caso, o próprio conceito de marketing de guerra santa - que pode ser relativizado, subvertido, alterado, ampliado e/ou (des/re) construído - é rasurado e colocado em trânsito: passa a se relacionar não só com as possíveis semelhanças entre gerenciamentos religioso/empresarial/militar, mas com o próprio modo como

\footnotetext{
${ }^{12}$ Tal fenômeno é recorrente em diversas agências evangélicas, como a IURD (Igreja Universal do Reino de Deus), que, ao mesmo tempo em que promove a intolerância às religióes de matriz afro, costumeiramente associadas "a uma miríade de encostos, capetas e demônios" (E. M. de A. MARANHÃO Fo, "Marketing de Guerra Santa": da oferta e atendimento de demandas religiosas à conquista de fiéis-consumidores. In: Horizonte, p. 213), valem-se da apropriação e (re) significação de alguns de seus referentes discursivos como estratégia de atração de fiéis "nativos" destas expressōes religiosas.

${ }^{13} \mathrm{O}$ epíteto santo deve ser entendido como alegoria, sinalizando para o contexto bélico das guerras santas promovidas por cristãos e não-cristãos durante a medievalidade - e "guerra santa configura-se em paradoxo, já que guerra sugere um contexto, e santa, outro." (E. M. de A. MARANHÁO Fo, "Marketing de Guerra Santa": da oferta e atendimento de demandas religiosas à conquista de fiéis-consumidores. In: Horizonte, p. 213).

${ }^{14}$ Nesta situação de marketing, típica da Idade Mídia (expressão de Stewart Hoover -S.M. HOOVER, Religion in the media age), as agências investem em terminologias adequadas a diferentes nichos de mercado. No caso de agências que têm surfistas como um de seus nichos mercadológicos, como a BDN, é comum a utilização de expressōes como "mergulhar na Palavra" e "surfar na onda do Espírito" para se referir à leitura da Bíblia e à oraçáo - e aludir a "Jesus como o primeiro surfista do mundo" por este ter caminhado sobre as águas. Agências com públicos-alvo distintos vão usar outras referências como forma de sedução dos mesmos.
} 
128 Eduardo Meinberg de Albuquerque Maranhão Filho

agências pensam, (re/des) significam e (re/des) apropriam conceitos e termos bélicos para promoverem-se no mercado religioso; apropriar-se de referentes bélicos no discurso pode ser considerado tanto um marketing de guerra santa, quanto um marketing com guerra santa.

\section{Nós vamos invadir sua praia! - e a UFSC. A BDN Floripa entre-mercados}

A BDN, fundada em 1999 na cidade de São Paulo por Rinaldo Luís de Seixas Pereira (apóstolo Rina), apresenta características múltiplas de um marketing de guerra santa, assim como suas filiais. A Bola de Neve Floripa (BDNF), conduzida por Rodrigo Aldeia (pastor Digão), por exemplo, pode ser entendida como praticante de estratégias de guerrilha santa, ao militar por terrenos mais segmentados que as líderes do mercado "neopentecostal", como Universal, Internacional, Mundial e Renascer, da qual é dissidente. ${ }^{15}$ Seu crescimento se associa a essa segmentação, nascida do pluralismo e neta da secularização, agregando sujeitos que transitam entre-lugares religiosos, entre-religiosidades, bem como sem-religiāo, desigrejados, dentre outros.

A BDNF apresenta ainda um marketing de defesa santa, em razão de sua liderança em um segmento específico, o dos surfistas evangélicos de Florianópolis, concorrendo pela preferência destes com os Surfistas de Cristo, Calvary Chapel, Sara Nossa Terra (do Morro das Pedras) e Renascer (do Campeche).

Com a mudança da sede, em 2010, do Rio Tavares para a Trindade-, onde se situa a UFSC (Universidade Federal de Santa Catarina) -, os esforços para a conquista dos universitários se intensificaram, ${ }^{16}$ tendo como consequência a substituição/renovação de grande parte dos fiéis. Inicia-se um processo de negociação entre a manutenção e o "resgate" de um público (surfistas, skatistas e afins) e a adesão de outro (universitários), demonstrando um trânsito entre-mercados e entre-segmentos. Apontando para o público inicial da BDNF, o presbítero André argumentou:

A maioria da galera que veio prá Floripa e tá na igreja veio prá pegar onda, não veio? Mas tem gente que tá com teia de aranha na prancha. Vamos fazer um trabalho com a galera do surfe da Praia Mole? Temos primeiro que preparar o plano espiritual prá não levar piau. Temos uma missão com os surfistas. $\mathrm{O}$ surfe precisa de referências, que somos nós, um canal vivo prá resgatar a galera do surfe. Vamos invadir e conquistar a Praia Mole. Temos de conquistar esta

\footnotetext{
${ }^{15}$ E. M. de A. MARANHÃO Fo, "Marketing de Guerra Santa": da oferta e atendimento de demandas religiosas à conquista de fiéis-consumidores. In: Horizonte, pp. 217-218.

${ }^{16}$ Anteriormente, a BDNF já havia empreendido outras formas de se aproximar dos estudantes da UFSC, como eventos de evangelismo e a constituição da Célula Trindade, próxima à universidade.
} 
galera prá Jesus! Vamos pegar onda junto e se precisar a gente já batiza uns ali dentro da água mesmo! ${ }^{17}$

Sobre os acadêmicos, Digão exclamou: "nossa missão é evangelizar esta faculdade!", ${ }^{18}$ objetivo reforçado por Diego Ferreira, líder da Célula UFSC da BDNF: ${ }^{19}$

O Bola foi do Rio Tavares para a Trindade pelo fato da UFSC estar aqui, e tudo girar em torno da Trindade. Na verdade, ouvi o apóstolo Rina dizer assim pro Digáo: "vai trocar de lugar, cara... o Bola do Rio Tavares vai mudar" e aí ele começou a buscar a direçáo do Senhor, e sentiram aqui na Trindade. Aqui com certeza é também mais bem localizado. ${ }^{20}$

A conquista de estudantes da universidade, através da mudança da sede e da oferta de um novo produto (serviço) religioso, a Célula UFSC, demonstra um marketing de guerra santa que se liquefaz em direção a nichos de mercado. As reuniôes dessa célula ocorrem às quintas-feiras ao meio-dia, próximo ao Restaurante Universitário e disputando espaço com um grupo de Capoeira Angola estabelecido, segundo seus líderes, desde 1987. Espaço, dia e horário escolhidos afiguram uma estratégia de flanqueamento santo, na qual a inovação está no modo de se aproximar do público, mais arrojado que o de outros grupos evangélicos que têm (ou tiveram) a UFSC como nicho. Outra forma de flanquear concorrentes, promovida pela Célula UFSC, está em oferecer produtos (ou serviços) próprios, como os shows de gospel pop o reggae performatizados pelo conjunto de evangelismo da BDNF. ${ }^{21}$

Dentre os mais recentes produtos da BDNF, destacam-se os ministérios Em Chamas (teatro), Bola Running (corrida), Bola Remo e Moto Clube Bola de Neve. A

\footnotetext{
${ }^{17}$ Presbítero André, dando recados antes da pregação Desertos da BDNF. Culto de 19/11/12. Anotaçóes de diário de campo.

${ }^{18}$ Culto dominical noturno da BDNF de 02/09/12.

${ }^{19}$ As células, na BDN, são encontros entre fiéis, mediados por líderes formados a partir de cursos próprios da agência. Tem o papel de atrair e organizar novos integrantes, reforçando a mensagem transmitida no culto principal, sanando dúvidas e propiciando espaço de interação e sensação de pertencimento. Em geral são realizadas em casas, tendo um líder e um anfitrião, mas podem ocorrer em outros espaços, como no caso da Célula UFSC, realizada em local público.

${ }^{20}$ Entrevista realizada após a primeira reunião da Célula UFSC, em 06 de setembro de 2012. Ferreira é líder da célula Trindade, localizada próximo à UFSC. Realizei, com Talita Sene, pesquisa de observação participante e entrevistas sobre a Célula UFSC durante todo segundo semestre de 2012. Tal pesquisa terá um artigo como produto.

${ }^{21}$ Estes shows foram realizados em duas sextas-feiras de novembro de 2012, no horário noturno, na praça Santos Dumont, ao lado da portaria principal da UFSC. Oferecer shows de gospel pop \& reggae não é original - a "inovaçáo" está na aproximação ousada. Até 08/12/12, o nome do conjunto era Ide, mas, por já haver banda registrada com este nome, o grupo encontra-se sem designaçáo.
} 
"criação" de novos produtos pode flanquear não só os concorrentes, como alguns dos próprios produtos da BDNF, por vezes os substituindo. ${ }^{22} \mathrm{O}$ marketing de guerra santa da BDNF transita entre-produtos e entre-serviços, em constante renovação.

Mas a BDNF planeja conquistar um público mais ampliado. Os líderes do Bola Running (BR $)^{23}$ convocaram: "Neste domingo teremos a Corrida Pague Menos, ${ }^{24}$ grande oportunidade que Deus nos deu para 'invadir', entáo postem em seus perfis de Face, partiu para correr e glorificar! Vamos conquistar a Ilha!", sinalizando para a beligerância: "Deus levantou um exército de guerreiros que treinam, correm e pregam o evangelho" - remetendo ao slogan "evangelizando com os pés" ${ }^{25}$ Postagens no Facebook são importantes na divulgação da BDNF, mediando a invasão de territórios espirituais e mercadológicos: "Galera, as novidades estão bombando! É a igreja avançando e saqueando o inferno! Neste sábado, 24/11/12, estreia o programa Bola de Neve Floripa na rádio Sara Brasil FM, das 18h às 19h. Sintoniza aí e dá um lo/ glória!”26 Os grifos, meus, demonstram a belicosidade do discurso da BDNF. Como vemos, as estratégias de "marketing santo" podem ser bricoladas, tendo fronteiras borradas - e a interpretação depende do referencial de análise do observador.

Os conceitos de marketing de guerra santa e seus desdobramentos (guerrilhal defesalataquelflanqueamento santos) devem ser percebidos a partir de seus possíveis sentidos heurísticos e didáticos - eles não dão conta da multiplicidade e abrangência de características de agências como a $\mathrm{BDN}$, em processo de derretimento e amoldamento de identidades e discursos, nem das experiências subjetivas de fiéis, constituídas por fluxos identitários, mnemônicos e narrativos.

\footnotetext{
${ }^{22}$ É possível, por exemplo, que o ministério de futebol da BDN, que liderei entre 2005 e 2006, tenha sido flanqueado pelo Bola Running a partir de sua criação, em 2010 - alguns dos praticantes do primeiro deslocaram-se para o segundo, como o próprio Digão. O ministério de futebol encontra-se praticamente inativo e o de corrida, em ampla expansão.

${ }^{23} \mathrm{Na} \mathrm{BDN}$, os ministérios representam coletivos de pessoas organizadas em torno de funçôes ou interesses comuns. Dentre estes, destacam-se: Assistência Social, Atacar, Atalaias, Boas-Vindas, Bolinha de Neve, Comunicação, Intercessão, Lojinha, Mergulhando na Palavra, Mulheres, Nova Vida, Radio, Recrie, Relações Internacionais, Sports, Singers, Surdos, Teens e Zeladoria. Células e ministérios funcionam como agenciadores da midiatizaçáo e consolidação da BDN, por estimularem a inserçâo sócio-religiosa do fiel e atuarem na adequação, reprodução e reiteração dos discursos da agência.

${ }^{24}$ Esta competição foi realizada na Avenida Beira-Mar, em 25/11/12, e patrocinada por uma rede de farmácias.

${ }^{25}$ Bola Running Floripa (Facebook). Disponível em: <www.facebook.com/bolarunningfloripa?ref=ts\&fref= ts)>. Acesso em: 19/11/12. Tenho acompanhado, com Talita Sene, treinos, competiçôes e reunióes do Bola Running. Tal observaçáo será descrita em artigo futuro.

${ }^{26}$ Programa Bola de Neve Floripa. Disponível em: <www.facebook.com/BoladeNeveFloripa?fref=ts $>$. Acesso em: 25/11/12.
} 


\section{Rasurando conceitos}

Outros conceitos/classificaçóes podem ser atribuídos a BDN ou a outras agências evangélicas. Dentre estes, pentecostal de terceira onda27, pentecostal de cura divina ${ }^{28}$, pentecostal autônoma ${ }^{29}$, pentecostal remasterizada $a^{30}$, neopentecosta ${ }^{31}$, pós-pentecosta ${ }^{22}$, neopentecostal de supergeração $0^{33}$ e agência evangélica de características majoritariamente neopentecostais.

Todos eles, contudo, podem ser desnaturalizados/desessencializados, ${ }^{34}$ destituídos de um sentido fixo. O mesmo ocorre com conceitos como mercado e economia religiosa, e com as possíveis equaçôes formadas a partir dos termos igrejalagêncial frrma e religiosalevangélica, por exemplo. Tais conceitos, classificaçóes e termos não dão suporte para as mediaçóes/negociaçôes/deslocamentos e agenciamentos de instituições, comunidades e pessoas. Ao pesquisador, cabe rastrear e perseguir etnograficamente esses movimentos - sensíveis, por vezes surpreendentes -, aprender com eles e náo se engessar com classificações.

O conceito de mercado ou economia religiosa, por exemplo, pode ser repensado quando entendemos que nem todos os sujeitos se encontram em contexto de seleção ou escolha: as pessoas podem converter-se ou/e aderir a instituiçóes por motivos variados, para além de uma mcdonaldização da fe $e^{35}$ - e agências religiosas podem ser criadas sem o objetivo de inserirem-se num contexto concorrencial. Pensar as religióes e/ou as religiosidades deve ter como suposto o esforço de náo ser reducionista ou essencialista, ainda que a fronteira entre essencialismo e não-essencialismo seja como uma fina camada de gelo.

\footnotetext{
${ }^{27}$ P. FRESTON, Breve história do pentecostalismo brasileiro. In: A. ANTONIAZZI, Alberto (org.). Nem anjos nem demônios: interpretaçóes sociológicas do pentecostalismo, pp. 67-159.

28 A. G. MENDONÇA, O Celeste Porvir: A Inserção do Protestantismo no Brasil.

${ }^{29} \mathrm{~J}$. BITTENCOURT F o, Remédio amargo. In: A. ANTONIAZZI (org.). Nem anjos nem demônios: interpretaçôes sociológicas do pentecostalismo.

${ }^{30}$ R. BITUN, A "remasterização" do movimento pentecostal. In: Ciberteologia, pp. 19-31.

${ }^{31}$ A. P. ORO, Podem passar a sacolinha: um estudo sobre as representaçōes do dinheiro no neopentecostalismo brasileiro. In: Cadernos de Antropologia, pp. 7-44; R. MARIANO, Neopentecostalismo: sociologia do novo pentecostalismo no Brasil.

${ }^{32}$ P. D. SIEPIERSKI, Pós-pentecostalismo e política no Brasil. In: Estudos Teológicos, pp. 47-61.

${ }^{33}$ E. M. de A. MARANHÃO Fo, Neopentecostalismo de supergeração. In: História Agora, pp. 342-362.

${ }^{34}$ E. M. de A. MARANHÁO Fo, Caia Babilônia: análise de uma canção religiosa a partir do contexto, poética, música, performance e silêncio. In: Revista Brasileira de História das Religiōes, p. 237.

${ }^{35}$ E. G. de M. PAEGLE, A "mcdonaldização" da fé - um estudo sobre os evangélicos brasileiros. In: Protestantismo em Revista, pp. 86-99; L.A.S. ROSSI, Jesus vai ao McDonalds: teologia e sociedade de consumo; L.M.S. MARTINO, Mídia e Poder Simbólico.
} 
132 Eduardo Meinberg de Albuquerque Maranhão Filho

Vários autores têm relativizado as teorias do mercado e da economia religiosa, como Duarte ${ }^{36}$, Frigerio $^{37}$, Maluf ${ }^{38}$ e Mariano $^{39}$. Relativizar tais teorias, entretanto, não as inviabiliza: provavelmente estas possam continuar dando substratos para se compreender tanto as identidades religiosas de pessoas, quanto as de comunidades e instituiçóes. Porém, ao defini-las como neopentecostais ou promotoras de um marketing de guerra santa, por exemplo, pode-se estabelecer, ao mesmo tempo, marcação identitária descritiva e prescritiva, reiterada pela nomeação e imersa num conjunto de relaçóes de poder assujeitadoras. ${ }^{40}$

A identidade religiosa, como as demais, é relacional ${ }^{41}$ e marcada pela diferença, havendo agenciamento/articulação da elaboração/transição identitária de si e do outro, em fluxo e contrafluxo contínuos. Contudo, as classificações identitárias sobre o outro nem sempre condizem com suas autodeclaraçóes - embora seja fundamental que o pesquisador leve as autodefiniçôes em conta.

Pensar em derretimento identitário implica a provisoriedadelefemeridadel transitoriedade da identidade - num processo de (re) elaboração, (des/re) construção, sem sentido fixo.

Ainda se pode indagar: existe uma identidade, ou esta é "imaginada", sempre em demanda, mas nunca atingida? Provavelmente as ideias de Agier, de "que toda declaração identitária, tanto individual quanto coletiva, é múltipla, inacabada, instável, sempre experimentada mais como uma busca que como um fato" ${ }^{42}$, e de Sanchis, de identidade como "o que o sujeito pretende ser, aos olhos dos outros e a seus próprios olhos, eventualmente até o que ele se esforça para se persuadir que ele é"ł3

Classificaçóes como a de identidade - bem como as anteriores - ainda que tenham fins heurísticos e pedagógicos, podem ser entendidas sob rasura: ${ }^{44}$ podem

\footnotetext{
${ }^{36}$ L. F. D. DUARTE, Três ensaios sobre pessoa e modernidade. Boletim do Museu Nacional.

${ }^{37}$ A. FRIGERIO, O paradigma da escolha racional. Mercado regulado e pluralismo religioso. In: Tempo Social, pp. 17-39.

${ }^{38} \mathrm{~S}$. W. MALUF, Além do templo e do texto: desafios e dilemas dos estudos de religião no Brasil. Antropologia em Primeira Mão, pp. 5-14.

${ }^{39}$ R. MARIANO, Usos e limites da teoria da escolha racional da religiáo. In: Tempo social, pp. 41-66.

40 Butler comenta a elaboração subjetiva a partir do assujeitamento, e estabelece uma grade de análise sobre nossa emersão como sujeitos a partir das relaçóes de poder, original e simultaneamente assujeitadoras e marcadas pela vulnerabilidade primária - carregando possibilidades de resistências criadoras em relaçáo à norma serializante da dominaçáo (J. BUTLER, The Psychic Life of Power).

${ }^{41}$ Sobre a relação com o Outro, ver J. BUTLER, Vida precária.

${ }^{42}$ M. AGIER, Distúrbios identitários em tempos de globalização. In: Mana, p. 10.

${ }^{43}$ P. SANCHIS, Inculturação? Da Cultura à Identidade, um Itinerário Político no Campo Religioso: o caso dos agentes de Pastoral negros, Religião e Sociedade, p. 62.

${ }^{44} \mathrm{Hall}$, retomando Derrida, argumenta que o sinal de rasura $(X)$, indica uma escrita dupla na qual o conceito-chave surge como mediador da inversáo e da emergência - a identidade sob rasura demonstra a provisoriedade
} 
ser utilizadas, ainda que a partir de uma (des/re) construção e (des/re) articulação. Sendo assim, o que proponho é pensar nos conceitos a contrapelo - a partir de sua precariedade e transitoriedade.

Caso possamos falar em uma "identidade institucional" da BDN, esta se caracteriza pelo trânsito entre mídia e espetáculo. Seu portal no ciberespaço, carro- chefe da agência, ${ }^{45}$ transporta o fiel a um universo de mercadorias oferecidas pelo Shopping da Bola ${ }^{46}$-, de Bíblias do Surfista a DVDs gospel e de pregação -, e conduz o mesmo a outros ambientes, como Bola TV, Bola Rádio, Mergulhando na Palavra e Mulheres da Bola.

Tal "identidade" é caracterizada pela ambiguidade entre um discurso derretido, flexível em relaçáo a usos e costumes, e um congelado, marcado pelo fundamentalismo, e refletida nos diferentes policiamentos em relação à sexualidade, afetividade e papéis de gênero, nas apropriaçōes e significaçóes em relação ao corpo e ao esporte e no uso das teologias do domínio, cura/libertação, saúde perfeita, prosperidade e batalha espiritual ${ }^{47}$.

$\mathrm{O}$ marketing de guerra santa da BDN, assinalado pelo uso de referentes bélicos em seu discurso, ou da guerra santa como marketing, agencia davis - crentes-guerreiros - a militar por territórios espirituais e seculares. A liquefação de sua identidade entre-lugares / entre-mercados carrega em seu bojo a permanência e intensificação da batalha espiritual como referente, que, com o tempo, cresce como bola de neve e se torna avalanche. Tal discurso beligerante derrete e desliza em direção aos fiéis - e ao mundo.

\footnotetext{
deste conceito, na qual a forma original não é mais suficiente para ser pensada. Entretanto, com a não superação dialética do conceito e sua não substituição por um diferente, este continua sendo pensado, ainda que sob perspectiva desconstrucionista, de modo diferente da forma original (S. HALL, Quem precisa da identidade? In: T. T. SILVA (org.), Identidade e diferença: a perspectiva dos estudos culturais). Maluf pensa, a partir das identidades sob rasura, na transitoriedade de sujeitos sob rasura: não há mais sujeitos, mas posiçóes de sujeito, bem como não há mais identidades, mas pontos de apego temporário (S. W. MALUF, Por uma antropologia do sujeito: da Pessoa aos modos de subjetivação. Parte I - Pessoa, Individualismo e crise do sujeito (no prelo). ${ }^{45}$ E. M. de A. MARANHÃO Fo, Neopentecostalismo de supergeração. In: História Agora, pp. 342-362.

${ }^{46} \mathrm{O}$ Shopping da Bola é a plataforma virtual de compras da BDN. Tais mercadorias são comercializadas também nos espaços internos das unidades da agência, as Lojinhas da Bola. Estas costumam compartilhar espaço com serviços como a Cantina da Bola e, no caso da BDNF, o Filadélfia Sushi Home.

${ }^{47}$ E. M. de A. MARANHÃO Fo, Caia Babilônia: análise de uma canção religiosa a partir do contexto, poética, música, performance e silêncio. In: Revista Brasileira de História das Religióes, pp. 234-272.
} 


\title{
"Porque do Senhor é a guerra": Preparando davis para a batalha
}

\author{
Como um menino e uma pedra lançada ao ar \\ É mais um Golias que vamos derrubar \\ Davi, Oficina G3
}

A BDN possui um discurso bélico que aponta para a teologia da batalha espiritual. Nesta agência, Satanás e seus demônios, diabos, capetas e zarapelhos fazem parte de uma força-tarefa obstinada em causar a derrota dos seres humanos, devendo ser combatidos com "unhas e dentes" espirituais.

Para efetuar a peleja contra o exército infernal, soldados especialistas, forjados através de cultos, reuniões celulares, ministérios e eventos - bases de treinamento e operações táticas - utilizam a intercessão (exorcismo/desobsessão/ desencapetamento) como bazuca espiritual para aniquilar entidades convocadas à guerra, como Exus-caveira, Pombagiras, Tranca-ruas, Maria Padilhas, ${ }^{48}$ Capa-pretas, Capirôtos, Carochos, Cramulhões, Coisas-ruins, Caramujos-no-lombo ${ }^{49}$ e outras sobras das Trevas. ${ }^{50}$ Tais esforços são responsáveis por retirar Lúcifer e seus tinhosos do corpo e da alma dos fiéis bem treinados. Agências como a BDN preparam milícias de davis a fim de reprimir golias diabólicos, envergonharem o Inferno $^{51}$ e derrubarem a Babilônia. ${ }^{52}$

\footnotetext{
${ }^{48}$ Desobsessão é um termo utilizado pelo kardecismo, por exemplo. Mas, escutei tal expressão em agências como a BDN, demonstrando a apropriação de vocábulos de outras religióes e apontando para um hibridismo. Nota-se nesse discurso maniqueísta um oponente a ser combatido, também chamado de adversário e inimigo. Orixás e entidades de religiōes de matriz afro são entendidos em muitas agências evangélicas como seres demoníacos, e resignificados a fim de afugentarem fiéis de tais expressóes religiosas e atraí-los.

${ }^{49}$ Caramujo-no-lombo foi locuçáo utilizada por Valdemiro Santiago, da IMPD (Igreja Mundial do Poder de Deus) em 27/11/12, durante programaçáo vespertina, como atestei através de observaçáo de seu programa televisivo. A frase foi "Você tava capetada, mulher - tava com o caramujo no lombo".

${ }^{50}$ A expressão sobras das Trevas foi referida por Digão: "Meu guia está falando comigo. Epa, não entendam errado, não tou falando de nenhum guia estranho. Meu guia é o Espírito Santo. Quem veio do "movimento" não confunda. Aqui nosso guia é outro. As sobras das trevas só imitam o que o Senhor faz." Pregaçáo Desertos, de Rodrigo Aldeia (pastor Digáo), em 18/11/12 (Notas de caderno de campo).

${ }^{51}$ A batalha contra o capeta é percebida nas liturgias: em 18/11/12, o presbítero Aldo, da BDN Floripa, comentou: "Igreja, vocês sabem por que batemos palmas no culto? É por que somos uma igreja avivada, cheia de fogo. Dá uma salva de palmas prá envergonhar o inferno!" (anotaçóes de caderno de campo). Envergonhar o Inferno é expressão recorrente na $\mathrm{BDN}$.

${ }^{52}$ Promover a queda da Babilônia, sendo esta uma alusão aos perigos do "mundo", é uma locução muito utilizada na BDN - demonstrada pela canção Caia Babilônia, espécie de hino da igreja, como expliquei em ocasiáo anterior (E. M. de A. MARANHÃO Fo, Caia Babilônia: análise de uma canção religiosa a partir do contexto, poética, música, performance e silêncio. In: Revista Brasileira de História das Religióes, pp. 234-272.)
} 
A canção Davi ensina: "os gigantes se levantam a cada dia, a todo o momento, nos tentando destruir", mas "do Senhor é a guerra, o inimigo vem ao chão na força do braço de Deus". ${ }^{33}$ Tal canção, que entre 2005 e 2009 foi muito interpretada na BDNF, cedeu espaço a outras que persistem promovendo um Senhor dos Exércitos: "vem marchando com seus cavaleiros, arvorando a sua bandeira, tem o cetro de ouro e a espada nas mãos" e "há um ruído se espalhando sobre a terra, de uma nação que se levanta para a guerra". ${ }^{54}$

O portal da BDN na internet convoca os fiéis a eventos que agenciam e reiteram a davidização. Em junho de 2012, a BDN Juquié realizou o Seminário de Cura Interior e Batalha Espiritual Vencendo os Gigantes. $\mathrm{O}$ anúncio refere o $1^{\circ}$ verso de Samuel (17:49): "Davi meteu a mão no alforje, apanhou uma pedra e arremessou-a com a funda, atingindo o filisteu com tanta força que a pedra se encravou na testa e o gigante caiu com o rosto em terra". A mão que se prepara para tomar a pedra ( figura 1) é hibridizada com uma onda, remetendo à expressão a grande onda vai te pegar, do jingle de abertura do portal da BDN (em sua versão até 2010). ${ }^{55} \mathrm{Na}$ mesma data, ocorreu na Praia Grande outro Seminário de Cura e Libertação da $\mathrm{BDN}$, diretamente associado à batalha e domínio espiritual (figura 2). ${ }^{56}$

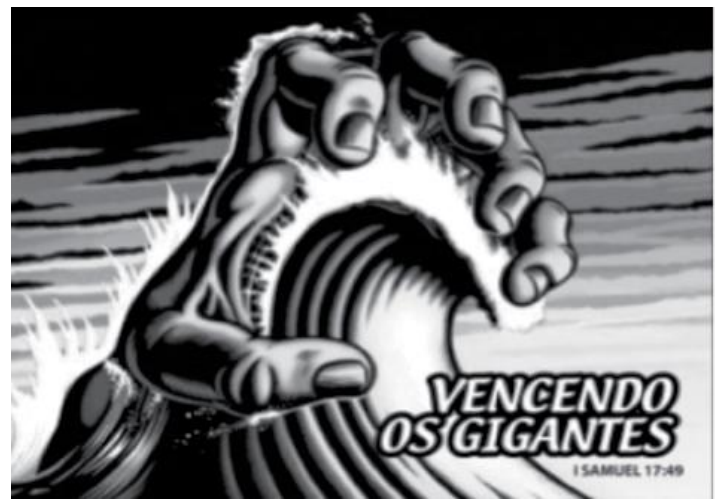

Figuras 1 e 2 -Seminário de Cura Vencendo os Gigantes e Seminário de Cura e Libertação.

\footnotetext{
${ }^{53}$ Esta sentença faz parte do $1^{\circ}$ verso de Samuel 17.47: "E saberá toda esta congregação que o Senhor salva, não com espada, nem com lança; porque do Senhor é a guerra, e ele vos entregará na nossa mão".

${ }^{54}$ Davi é uma canção da Oficina G3. As cançōes O chão vai tremer, do Toque no Altar, e Eu sou de Cristo, de David Quinlan, foram performatizadas no culto de 25/11/12, dentre outras, e entremeadas por brados de Digão conclamando a igreja a marchar e conquistar.

${ }^{55}$ Os seminários de cura e libertação da BDN costumam ser ministrados por pessoas convidadas. No caso do realizado em Jequié, a missão ficou a cargo do Ministério Apostólico O Libertador de Israel, liderado pelo apóstolo Sírio e a pastora Vanda de Olivença, ambos da Bahia.

${ }^{56}$ Ambos foram realizados entre 8 e 10 de junho de 2012. As inscrições davam direito à apostila e o valor era R\$30, indicando uma padronizaçáo do serviço. Notícias. Bola de Neve Church. Disponível em: <www. boladeneve.com/noticias/boladeneve/jequie-convida-para-seminario-de-cura>. Acesso em: 02 jun. 2012.
} 
136 Eduardo Meinberg de Albuquerque Maranhão Filho

Para combater o Ferrabrás e suas hostes mefistofélicas, os davis da BDN são moldados através de Congressos de Batalha Espiritual. A imagem seguinte remete $\grave{a}$ camuflagem militar, com a palavra guerra repetida, compondo a expressão do Senhor é a guerra. Ao lado do capacete, a exortação: Prepare-se para batalha! (figura 3).

Marechais do Reino de Deus como Silas Malafaia, RR Soares, Valnice Milhomens, Chuck Pierce, Neuza Itioka e Rinaldo Seixas dotam tais eventos de eficácia simbólica performativa, apresentam estratagemas de tomada de territórios espirituais e seculares, exaltam a obediência do crente-soldado e imprimem líderes como porta-vozes autorizados e autoritários ${ }^{57}$ - vozes e imagens de Deus na Terra, por vezes sacralizados por fiéis. Ao gladiador-evangélico convém ser disciplinado, pois, como nota Mariano, os neopentecostais "creem que o que se passa no 'mundo material' decorre da guerra travada entre as forças divina e demoníaca no 'mundo espiritual'". ${ }^{58}$

A invasão de territórios é conduzida por ministérios de evangelismo como o Atacar!, instalado na BDNSP, quartel-general responsável pela convocação/ formação de davis, e função logística de criar e gerenciar ardis de inserção no "mundo". Seu slogan "a Igreja avança, o inferno retrocede" - e o anúncio de que "milhares de vidas sob o comando do inferno aguardam ansiosas a manifestação dos Filhos de Deus" - demonstram a ofensiva contra o Príncipe das Trevas e o Império do Mal. As figuras seguintes (3 e 4) demonstram a apropriação que a BDN faz de referentes bélicos.
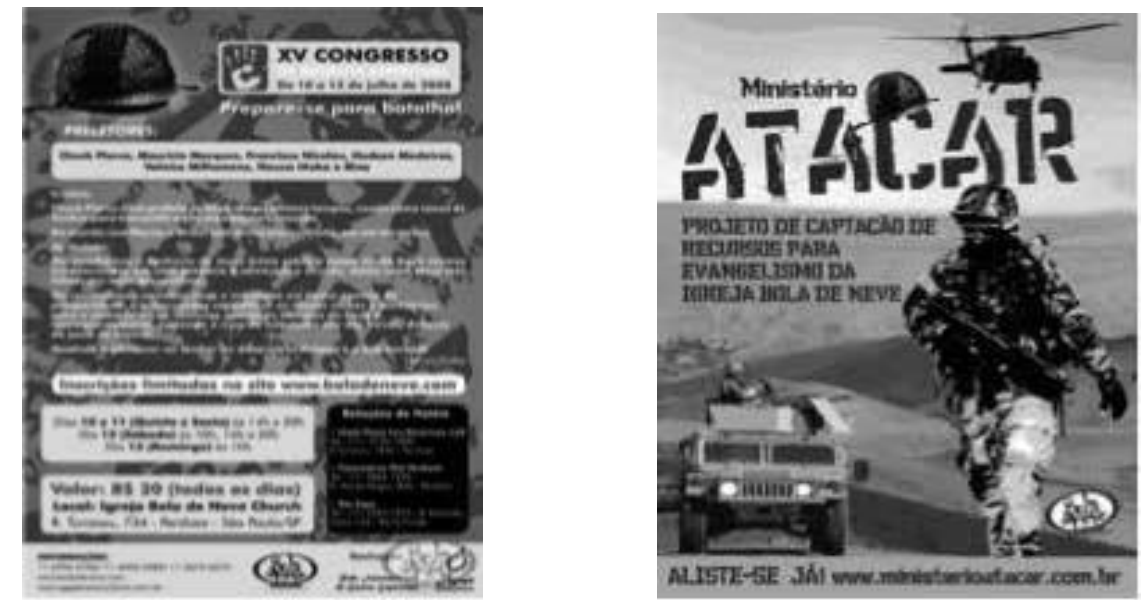

Figuras 3 e 4 - Congresso de Batalha Espiritual (2008) ${ }^{59}$ e Ministério Atacar (2009). ${ }^{60}$

\footnotetext{
${ }^{57}$ P. BOURDIEU, A economia das trocas linguisticas (o que falar quer dizer), p. 105.

${ }^{58}$ R. MARIANO, Neopentecostalismo: sociologia do novo pentecostalismo no Brasil, p. 113.

${ }^{59}$ News. Disponível em: <www.boladenevechurch.com.br/admin/conteudos/images/news_081201.jpg>. Acesso em: 3 novembro 2009.

${ }^{60}$ News. Disponível em: <www.boladenevechurch.com.br/admin/conteudos/images/news_ 080227.jpg>. Acesso em: 3 novembro 2009. Analisarei mais detalhadamente este ministério em trabalho posterior.
} 
Os discursos referentes à derrocada das legióes satânicas são reiterados pelos mais novos serviços oferecidos pela BDNF, como a Célula UFSC e os ministérios Remo, Running, Em Chamas e Moto Clube, demonstrando a articulação entre novos serviços - bases de agenciamento/treinamento de davis -, e o discurso militar, já "tradicional" da BDN.

Em 8/12/12, o conjunto musical de evangelismo da BDNF alargou suas estacas, ergueu sua tenda e apresentou-se durante o Reveza UFSC, competição esportiva da universidade, combinando estratégias de invasáo articuladas pela Célula UFSC e o Bola Running (BR) - demonstrando a corrida pelas almas dos universitários, fazendo o diabo correr pro lado oposto - e dando novo sentido à ideia de Agier de uma "identidade mais como busca do que como chegada" ${ }^{1}$, já que a busca assume duplo sentido - correr atrás de si e dos fiéis. A maioria das cançóes do conjunto tinha a batalha espiritual como tema e, como é de costume, ao menos uma delas aludia ao rei Davi, auxiliado pelos crentes-guerreiros: "a geração de Samuel está se levantando em todo lugar, geração que depóe Saul, geração que unge Davi". ${ }^{62}$ Novamente, derretimento e solidificação são chamados à frente de batalha: novos serviços (BR + Célula UFSC + conjunto de gospel pop \& reggae) apresentam cançóes evangelísticas contemporâneas permeadas por linguagem coloquial, trazendo como resultado um discurso conservador na BDN, o bélico. São odres novos contendo vinho velho - e congelado. ${ }^{63}$

Invadir a universidade, saquear o Inferno e dominar territórios não está relacionado apenas ao mundo sobrenatural - nem ao mercado religioso. ${ }^{64} \mathrm{Tal}$ como Davi, guerreiro que se torna rei das naçóes - apoiado pela geração de Samuel-, o crente deve ocupar outros espaços, como o da política.

\section{"A igreja avança, o diabo retrocede": Preparando davis para a política}

Para que a igreja avance, davis são preparados para atuar em vários fronts. Um deles é a mídia evangélica/secular, vinculando cultura gospe ${ }^{65}$ e esfera pública, agenciando o estímulo/apoio a candidaturas evangélicas, nas quais slogans

\footnotetext{
${ }^{61}$ M. AGIER, Distúrbios identitários em tempos de globalização. In: Mana, p. 10.

${ }^{62}$ Geração de Samuel, de Fernandinho.

${ }^{63}$ Para diálogos com a ideia de odres e vinhos, ver M. N. CUNHA, Vinho novo em odres velhos. Um olhar comunicacional sobre a explosão gospel no cenário religioso evangélico no Brasil.

${ }^{64}$ Outra locução "nativa" empregada pela BDN é saquear o Inferno, como se vê na frase retirada do perfil do Moto Clube BDNF no Facebook: "Mais uma frente começando, é a igreja avançando e saqueando o inferno! Mais que um moto clube, uma família. Um propósito e uma missão!” Moto Clube BDN Floripa. Disponível em: <www.facebook.com/MotoClubeBolaDeNeveFloripa>. Acesso em: 28 nov. 2012.

${ }^{65}$ Tal expressão é utilizada por pesquisadores como Magali Cunha (M. N. CUNHA, A Explosão Gospel. Um olhar das ciências humanas sobre o cenário evangélico contemporâneo).
} 
138 Eduardo Meinberg de Albuquerque Maranhão Filho

como "irmão vota em irmão" (ou "davi vota em davi”) são preciosos: A inserção evangélica no "mundáo" representa a tomada de posiçóes ocupadas por diabos, diachos, dianhos e diás - e seus representantes na Terra.

Até alguns anos, como argumenta Bourdieu, a eficácia simbólica de que dispunham os líderes religiosos dependia de "ocultar a si mesmos e aos outros seus interesses políticos (ou seja, em linguagem 'pagã', interesses 'temporais')" ${ }^{66}$ No Brasil, até recentemente os pentecostais pregavam a exclusão do fiel "deste mundo" - notadamente da mídia e da política -, o que não ocorre mais, como vemos na disposição de algumas agências (neo) pentecostais em estimular candidaturas. Como sustenta Mariano, a doutrina do domínio pensa promover uma espécie de recristianização da sociedade “"pelo Alto', quer dizer, pela via político-partidária e pela mídia eletrônica". ${ }^{67}$

Em 2008, a BDN Santos foi homenageada pela Câmara de Vereadores local por conta de seu aniversário de quatro anos, indiciando uma das primeiras articulaçóes da BDN com o mundo político. Após a entoação de cânticos gospel pelos davis santistas e entrega de placa em homenagem ao pastor Eric Vianna, o presidente da sessão declarou que "essa família, essa Igreja, está fazendo a diferença nessa cidade". Vianna explicou que "os reis deste mundo" estavam "reconhecendo o trabalho dos filhos do Rei dos reis", e que "por muito tempo a Igreja foi vidraça do diabo, mas que hoje jogamos as pedras na vidraça do mundo." (figura 5$)^{68}$

Quebrar a vidraça e dominar o mundo prescinde da eleição de davis - candidatos - guerreiros da BDN. Eduardo Tuma, candidato da BDNSP a vereador, foi eleito em 2012 pelo PSDB (coligação PSDB/PSD/PR/DEM), com 28.756 votos ( figura 6). Sua campanha foi alvo de polêmicas: um dos "santinhos" distribuídos por seu comitê veiculava a imagem e apoio do ex-deputado estadual tucano Ricardo Montoro (filho de um dos fundadores do PSDB, André Franco Montoro), que encaminhou carta à executiva paulistana pedindo punição máxima (expulsão) de Tuma, acusando-o de falsidade ideológica. Tuma também veiculou sua campanha ao apoio de Bruno Covas, que "disparou" comunicado esclarecendo náo ter autorizado a propaganda. ${ }^{69}$

Outro candidato foi Tanio Barreto, pela coligação $\mathrm{PSD} / \mathrm{PP}$ a vereador, com apoio da BDN Floripa. Reproduzo carta de Digão, endereçada ao mailing list da BDNF e acompanhada de "santinho" ( figura 7):

\footnotetext{
${ }^{66} \mathrm{P}$. BOURDIEU, A economia das trocas simbólicas.

${ }^{67}$ R. MARIANO, Neopentecostalismo: sociologia do novo pentecostalismo no Brasil, p. 44.

${ }^{68}$ News. Disponível em: <www.boladenevechurch.com.br/admin/conteudos/images /news_ 080625.jpg>. Acesso em: 3 maio 2009. Esta homenagem se realizou em vinte e um de junho de 2008.

${ }^{69}$ Filho de Montoro pede expulsão de colega sob acusação de fraude. Disponível em: <www1.folha.uol.com.br/ poder/1169752-filho-de-montoro-pede-expulsao-de-colega-sob-acusacao-de-fraude.shtml>. Acesso em: 22 out 2012.
} 
A Paz do Senhor, estamos perto de momentos decisivos na nossa cidade. Como cristãos, temos que participar e se empenhar para vermos pessoas de família e de caráter que vão representar não somente nós cristãos, mas todo aquele que precisar ser assistido. A palavra de Deus nos diz que quando o justo governa o povo se alegra. Um candidato que indico para colocarmos como representante da sociedade junto à câmara dos vereadores é o Tanio Barreto 55005. Há quinze anos conheço o trabalho que ele realiza junto aos mais necessitados (...). Frequentador da igreja, tem se envolvido em projetos que realizamos junto às comunidades carentes e demonstrando exteriormente o que é no seu interior. Vamos juntar esforços nesses últimos dias que antecedem as eleições para colocarmos um representante não somente da igreja, mas também de toda a sociedade. Tanio Barreto 55005. Pr. Digão
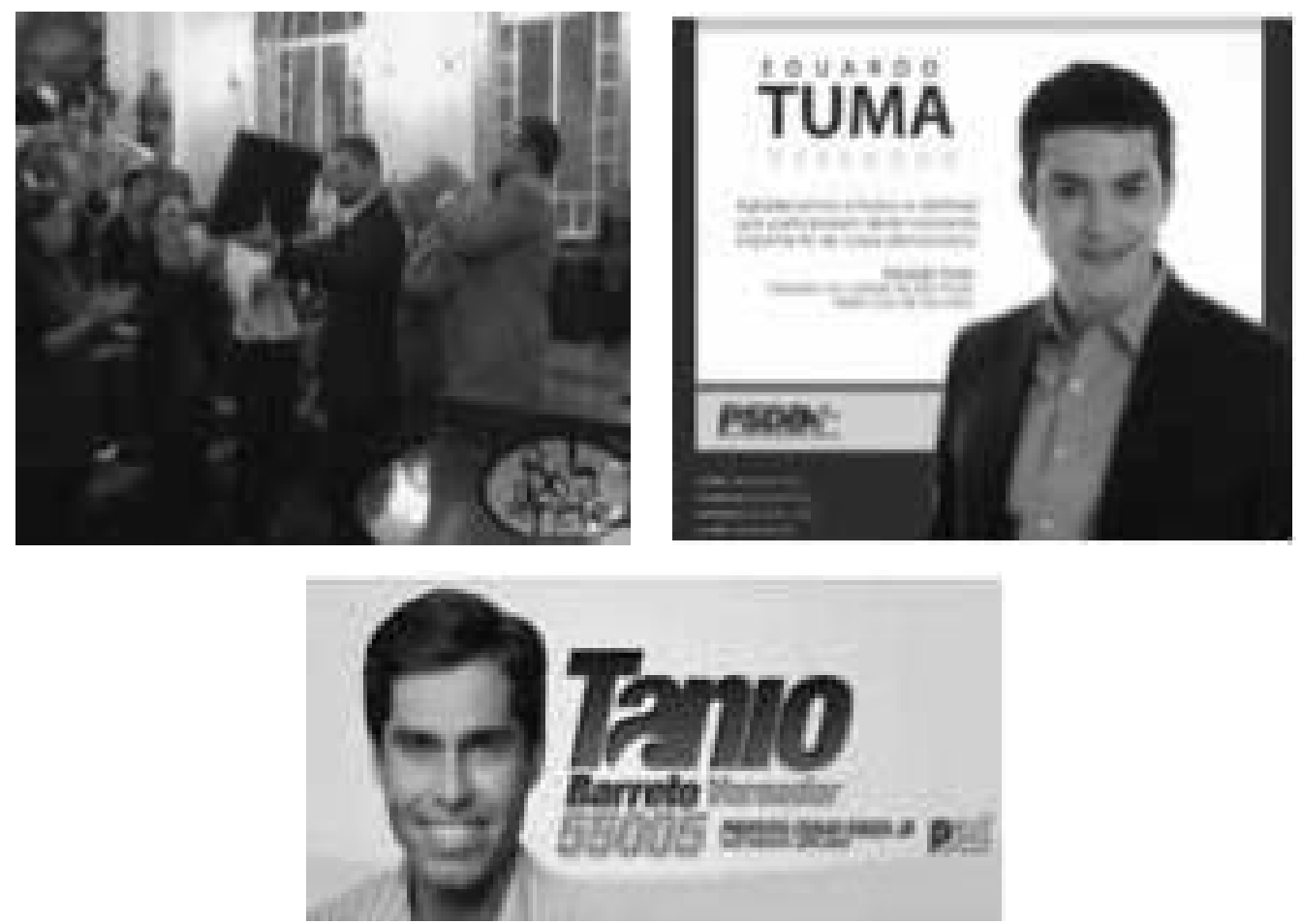

Figuras 5 a 7 - Homenagem da Câmara de Santos à BDN local: ${ }^{70}$ agradecimento de Tuma aos eleitores" ${ }^{71}$ "santinho" de Barreto. ${ }^{72}$

Acompanhei, em 02/09/2012, culto dominical em que a candidatura de Barreto foi apresentada. Após o louvor, Digão assumiu o microfone e contou sua

\footnotetext{
${ }^{70}$ News. Disponível em: <www.boladenevechurch.com.br/admin/conteudos/ images/news_080625.jpg>. Acesso em: 3 maio 2009.

${ }^{71}$ Agradecimento de Eduardo Tuma aos eleitores. Disponível em: <www.eduardotuma.com.br/>. Acesso em: 05 nov. 2012.

${ }^{72}$ Recebido por e-mail em 26/09/2012, juntamente com carta do pastor Digáo indicando a candidatura.
} 
trajetória. Relatou ter sido criado em lar evangélico e se desviado, retornando à fé através de amigo. Este foi responsável por resolver pendência judicial na qual a BDN se envolveu em 2007, e que fizera com que fechasse as portas por alguns meses, reabrindo graças à sua intervenção. Tal sujeito era Barreto, que subiu ao palco para narrar seu testemunho, contando que era chamado de "sem-terra" pelos surfistas graças a sua baixa condição econômica, que comia "banana com pão de manhã e pão com banana à tarde" e que, após ter colocado Deus à prova, dizimando 25 reais, "o chefe da Mormaii me chamou, me colocou na equipe principal e voltei com 3.500 dólares do campeonato.” Após obedecer a Deus contribuindo financeiramente, tornou-se referência no surfe e próspero a ponto "das pessoas me confundirem com o filho do presidente da República".

Digão comentou que a igreja deveria "honrar a quem tem honra" e que "é importante investir nos que são nossos", brincando: "se ele fizer algo errado após eleito, levamos ele na salinha de intercessão e batemos nele". Em seguida, reforçou a importância do dízimo, como forma de "transformar vidas e abrir igrejas", sendo tarefa "para os que entendem", e que estes "seriam honrados por Deus". Amoldar-se a Deus, submeter-se aos líderes e guerrear através de cânticos espirituais foram os motes de sua pregação. Para a BDN, saquear o Inferno se prorroga na canção gospel: As Águias Teens foram chamadas ao palco e tocaram hits recentes sobre batalha, acompanhadas por uma dançarina que prestava continências e pelo presbítero André, que entoava seu shofar. O cantor do conjunto - presbítero Ibirá - repetia de forma mântrica: a igreja avança, o diabo retrocede.

Esta liturgia permite que percebamos uma das ambiguidades da BDN: de um lado do ringue, um discurso congelad $^{73}$ se traja com as cores do fundamentalismo, de outro, um discurso coloquial é moldado pelo derretimento - ambos afinados para atender as expectativas dos fiéis. A Santíssima Trindade do neopentecostalismo se faz presente nas figuras da prosperidade, da batalha e do domínio santo. No front, filisteus demoníacos são aniquilados por artilharia constituída por uma única pedra lançada pelos davis - míssil contra o capeta -, a obediência. A BDN avança, o diabo retrocede.

\section{Considerações inconclusivas}

As referências militares são identificadas pelos crentes como representações de significados espirituais, ${ }^{74}$ e as forças satânicas, como expressóes de dificuldades

\footnotetext{
${ }^{73}$ E. M. de A. MARANHÃO Fo, Sensualidade e interdição do desejo na Bola de Neve Church. In: Via Teológica.

${ }^{74}$ Expressōes bélicas como defesa, ataque, estratégias, avanço, expansäo, arma espiritual, conquista de territórios e remover inimigos são referentes discursivos recorrentes e que demonstram o contexto militar esperado aos que obedecem a um Senhor dos Exércitos.
} 
emocionais, familiares, financeiras e profissionais. Mas também são vistas de modo literal - batalhóes encapetados militam pela alma dos humanos: é uma guerra em outro domínio, o do espírito, não separado do real - e desta forma, as citaçóes belicosas devem ser vistas de modo polissêmico. Termos bélicos como referentes discursivos tem objetivo claro: auxiliar na instituição de gladiadores evangélicos que batalham contra potestades demoníacas, que também transitam entre os sentidos figurado e literal.

$\mathrm{O}$ marketing de guerra santa da BDN, articulando um marketing com a guerra santa, convoca diversos personagens para seu teatro de operaçóes de guerra espiritual. ${ }^{75} \mathrm{Na}$ zona de combate, como em um tabuleiro de xadrez, encontram-se peças escuras e claras: O Cáo agencia as Trevas, faz de pessoas cavalos e comanda hordas constituídas por erês, pés-de-bode, zarapelhos e ferrabrases. Falanges de rafaéis, gabriéis, querubins e serafins precipitam como avalanche celestial, auxiliando plêiades de crentes-soldados a sabotar os planos demoníacos e encaminhar Satã para o lugar de onde não deveria ter saído.

Tais davis, treinados a partir de diversos discursos, atuam na reiteração de normas, agenciam soldados e consolidam a marca BDN no mercado. Dentre as fronteiras que instauram a dicotomização entre davis e golias, o principal marcador é a obediência aos marechais-sacerdotes. Um bom davi não somente entende a Palavra, mas tem revelação, disciplina e não peca: sabe marchar direito. A este, Deus é fiel-desobedecer, ao invés de reiterar, torna davis passíveis de goliação.

O preparo de davis é mediado pela articulação entre um discurso marcial caracterizado pela permanência/congelamento e novos produtos que representam um marketing de guerra santa que transita/derrete por entre-lugares religiosos, entre-públicos e entre-serviços, vinculando inovaçôes e continuidades: a bola de neve cresce e se adapta com o movimento, mas estacionar faz parte do trânsito.

Como reforcei no início do artigo, pensar em agências como a BDN a partir de categorias como a do marketing de guerra santa, por exemplo, náo dá conta dos múltiplos agenciamentos institucionais, coletivos e subjetivos relativos à mesma. Conceitos como este servem apenas como recursos didáticos/heurísticos e propositores de diálogos - podendo ser rasurados.

Este trabalho não se pretende conclusivo - outras observaçóes poderão provocar deslizamentos em direção a novos fiordes de conhecimento. Espero que algumas das ideias apresentadas aqui possam auxiliar na fermentação de debates - e que estes venham tal qual uma avalanche.

\footnotetext{
75 Teatro de operaçóes de guerra é locução utilizada por militares para referirem-se a campos de batalha, ou o espaço geográfico - terrestre, aéreo e marítimo - envolvido nas operaçóes militares de uma guerra.
} 
142 Eduardo Meinberg de Albuquerque Maranhão Filho

\section{Referências}

AGIER, M. Distúrbios identitários em tempos de globalização. In: Mana, 7, 2, 2001, pp.7-33.

BHABHA, H. K. O local da cultura. Belo Horizonte: Ed. UFMG, 1998.

BITTENCOURT Fo, J. "Remédio amargo". In: ANTONIAZZI, A. et al. Nem anjos nem demônios: interpretaçóes sociológicas do pentecostalismo. Petrópolis, Vozes, 1994, pp. 24-33.

BITUN, R. A "remasterização" do movimento pentecostal. In: Ciberteologia, 23, 2009, pp. 19-31.

BOURDIEU, P. A economia das trocas linguísticas (o que falar quer dizer). São Paulo: EDUSP, 1996.

- A economia das trocas simbólicas. São Paulo: Editora Perspectiva, 1992.

. Genèse et structure du champ religieux. In: Revue Française de Sociologie, XII , 1971, pp. 295-334.

BUTLER, J. The Psychic Life of Power. Stanford: Stanford Univ. Press, 1997.

. Vida Precária. In: Contemporânea, 1, 2011, pp.13-33.

CAMPOS, L. S. Teatro, templo e mercado: organizaçáo e marketing de um estabelecimento neopentecostal. Rio de Janeiro: Vozes, 1997.

CUNHA, M. N. A Explosäo Gospel. Um olhar das ciências humanas sobre o cenário evangélico contemporâneo. Rio de Janeiro: Mauad, 2007.

, Vinho novo em odres velhos. Um olhar comunicacional sobre a explosão gospel no cenário religioso evangélico. Doutorado em Ciências da Comunicação, 2004, Universidade de São Paulo. Orientador: Luiz Roberto Alves.

DUARTE, L.F.D. Três ensaios sobre pessoa e modernidade. In: Boletim do Museu Nacional, 41 (1983).

FRESTON, P. Breve história do pentecostalismo brasileiro. In: ANTONIAZZI, Alberto (org.). Nem anjos nem demônios: interpretaçóes sociológicas do pentecostalismo. Petrópolis: Vozes, 1994, pp.67-159.

FRIGERIO, A., O paradigma da escolha racional. Mercado regulado e pluralismo religioso. In: Tempo Social, 2, 20, 2008, pp.17-39.

GUERRA, L., As influências da lógica mercadológica sobre as recentes transformaçōes na Igreja Católica. In: REVER, 2, 2003, pp.1-23.

HALL, S. Quem precisa da identidade? In: SILVA, T. T. (org.) Identidade e diferença: a perspectiva dos estudos culturais. Petrópolis, Vozes, 2000, pp. 103-133.

HOOVER, S.M. Religion in the media age. New York: Routledge, 2006.

MALUF, S. W., Além do templo e do texto: desafios e dilemas dos estudos de religiáo no Brasil. In: Antropologia em Primeira Mão, 124, 2011, pp.5-14.

, Por uma antropologia do sujeito: da Pessoa aos modos de subjetivação. (mimeografado, no prelo).

MARANHÃO Fo, E. M. de A., Caia Babilônia: análise de uma canção religiosa a partir do contexto, poética, música, performance e silêncio. In: Revista Brasileira de História das Religiôes. ANPUH, Ano V, 13, 2012, pp. 234-272. 
, "Marketing de Guerra Santa": da oferta e atendimento de demandas religiosas à conquista de fiéis-consumidores. In: Horizonte, Belo Horizonte, 10, 25,2012, pp.201-232.

, Neopentecostalismo de supergeração. In: História Agora, São Paulo, v.1, n.10, 2010, pp. 342-362.

, Sensualidade e interdição do desejo na Bola de Neve Church. In: Via Teológica, Curitiba, 18, 2009, pp. 147-169.

MARIANO, R. Neopentecostalismo: sociologia do novo pentecostalismo no Brasil. São Paulo, Loyola, 1999.

, Usos e limites da teoria da escolha racional da religiáo. In: Tempo social, 20, 2 (2008), pp. 41-66.

MARTINO, L. M. S. Mídia e Poder Simbólico. São Paulo: Paulus, 2003.

MENDONÇA, A. G. O Celeste Porvir: A Inserção do Protestantismo no Brasil. São Paulo, Ediçóes Paulinas, 1984.

ORO, A. P. Podem passar a sacolinha: um estudo sobre as representaçóes do dinheiro no neopentecostalismo brasileiro. In: Cadernos de Antropologia, 9 (1992), pp.7-44.

PAEGLE, E. G. de M. A “mcdonaldização” da fé - um estudo sobre os evangélicos brasileiros. In: Protestantismo em Revista, 17, 2008, pp.86-99.

ROSSI, L.A.S. Jesus vai ao McDonalds: teologia e sociedade de consumo. Curitiba: Champagnat, 2011.

RIES, A., TROUT, J. Marketing de Guerra. São Paulo: McGraw-Hill, 1989.

SANCHIS, P., Inculturação? Da Cultura à Identidade, um Itinerário Político no Campo Religioso: o caso dos agentes de Pastoral negros. In: Religião e Sociedade, Rio de Janeiro, 20, 2 (1999): pp.55-72.

SIEPIERSKI, P. D., Pós-pentecostalismo e política no Brasil. In: Estudos Teológicos, Rio Grande do Sul, IECLB, 37, 1 (1997): pp.47-61.

Recebido: 08/12/2012

Aprovado: 17/12/2012 